CLINICAL STUDY

\title{
The effects of long-term metformin treatment on adrenal and ovarian steroidogenesis in women with polycystic ovary syndrome
}

\author{
J Vrbíková, M Hill, L Stárka, D Cibula ${ }^{2}$, B Bendlová, K Vondra, J Šulcová and M Šnajderová ${ }^{1}$ \\ Institute of Endocrinology, Prague, Czech Republic, ${ }^{1}$ 2nd Pediatric Department of the 2nd Medical Faculty, Charles University, Prague, Czech Republic \\ and ${ }^{2}$ Department of Obstetrics and Gynecology of the 1st Medical Faculty, Prague, Czech Republic \\ (Correspondence should be addressed to J Vrbíková, Institute of Endocrinology, Národní 8, Prague 1, 116 94, Czech Republic; Email: jvrbikova@endo.cz)
}

\begin{abstract}
Objective: To evaluate adrenal and ovarian steroidogenesis before and after long-term treatment with metformin in women with polycystic ovary syndrome (PCOS).

Design and Methods: Twenty-four women with PCOS were evaluated before and after treatment $(27 \pm 4$ weeks) with metformin (1000 mg/day) using adrenocorticotrophin (ACTH), GnRH analogue and oral glucose tolerance (oGTT) tests. For statistical evaluation, ANOVA and Wilcoxon's test were used.

Results: In $58 \%$ of the women a significant improvement in menstrual cyclicity was observed. No significant change in basal steroid levels was found. After ACTH stimulation, a significant decrease in the activity of $3 \beta$-hydroxysteroid dehydrogenase in $C_{21}$ steroids $(P<0.05)$ and in $17 \beta$ hydroxysteroid dehydrogenase $(P<0.01)$ was observed, as was an increase in the activity of C17,20-lyase in the $\Delta^{4}$ pathway $(P<0.01)$. A significant growth in the dehydroepiandrosterone (DHEA)/DHEA-sulfate ratio $(P<0.05)$ was detected. With regard to ovarian steroidogenesis, a significant decrease in the stimulated levels of testosterone $(P<0.05)$, index of free testosterone $(P<0.01)$, LH $(P<0.05)$ and oestradiol $(P<0.01)$, and an increase in the levels of 17 hydroxypregnenolone $(P<0.05)$ were detected. In the indices of ovarian enzyme activities, we observed a significant decrease in $3 \beta$-hydroxysteroid dehydrogenase in $C_{21}$ steroids $(P<0.01)$, in $\mathrm{C} 17,20$-lyase in the $\Delta 5$ pathway $(P<0.01)$, in $17 \beta$-hydroxysteroid dehydrogenase $(P<0.05)$ and in aromatase. In glucose metabolism, a tendency towards reduction in the homeostasis model assessment (HOMA)-R (for insulin resistance) and HOMA-F (for $\beta$ cell function) was detected. In addition, an increase in the levels of $\mathrm{C}$ peptide during oGTT was observed $(P<0.01)$.

Conclusions: Long-term metformin treatment reduced various steroid enzymatic activities both in the ovary and the adrenal glands, without apparent changes in basal steroid levels and in insulin sensitivity.
\end{abstract}

European Journal of Endocrinology $144619-628$

\section{Introduction}

Polycystic ovary syndrome (PCOS) is probably the most common endocrinopathy in women of childbearing age. It is invariably associated with hyperandrogenism and, in many cases, with insulin resistance. Insulin has a direct stimulatory effect on ovarian steroidogenesis in vitro (1), decreases the synthesis of sex hormonebinding globulin (SHBG) in the liver (2), and inhibits liver production of insulin-like growth factor-binding protein-1, resulting in an increased bioavailability of insulin-like growth factor-I (2). PCOS is commonly considered in relation to the increased ovarian activity of C17-hydroxylase, and to the relatively less stimulated activity of C17,20-lyase (3); insulin is probably involved in their regulation. Both of these enzyme activities are also important for adrenal steroidogenesis. It is possible that insulin (4) or oestrogens (4-6) are involved in the regulation of these enzymes in the adrenal glands. The origin of hyperandrogenism in women with PCOS has not yet been clearly discerned. A large number of women with PCOS, perhaps as many as $40-60 \%(3,7)$ have, in addition to ovarian hyperandrogenism, signs of adrenal androgen excess, defined for example by high levels of dehydroepiandrosterone-sulfate (DHEAS).

Metformin as an insulin-reducing agent is considered to be a promising treatment for women with PCOS. It has multiple mechanisms of action, including the inhibition of gluconeogenesis in the liver, and the stimulation of peripheral glucose uptake (8); interestingly, there is also 
some evidence for the direct inhibitory effect of metformin on ovarian steroidogenesis (9). The literature to date contains only few data about the effects of metformin on adrenal steroidogenesis in women with $\operatorname{PCOS}(10,11)$.

The aim of this study was to evaluate the effect of metformin on both ovarian and adrenal steroidogenesis in long-term therapy in women with PCOS. The majority of studies with insulin-sensitizing agents have used basal steroid levels before and after such therapy with contradictory results, either finding a reduction in androgens (12-18) or not finding such a reduction (19-21). We attempted the use of the product/precursor ratios of various steroids after specific stimulation (adrenocorticotrophin (ACTH) test for adrenals and gonadotrophin-releasing hormone (GnRH) analogue (GnRHa) test for ovaries), in order to define different enzymatic activities as entities not directly measurable in vivo. Subsequently, insulin resistance and secretion were assessed using the oral glucose tolerance test (oGTT) and homeostasis model assessment (HOMA) to define the possible effects of metformin on these parameters.

\section{Subjects and methods}

\section{Patients}

The study group consisted of 24 oligo/amenorhoeic women with PCOS matching National Institute of Health (NIH) criteria (22), all with the clinical manifestation of hyperandrogenaemia such as hirsutism and/or acne and with an elevated free testosterone index. Vaginal ultrasonography was performed, with polycystic ovaries being found in 17 of the patients (71\%), multifollicular ovaries (multiple subcortical follicles with no increase in the volume of the ovarian stromal area) in five patients (criteria according to Adams et al. (23)), and ovaries sonographically of normal appearance in two cases. Thyroid dysfunction, hyperprolactinaemia, hypercortisolism and the late onset of congenital adrenal hyperplasia were all excluded using the appropriate tests. None of the patients had taken oral contraceptives or any other steroid medication during the preceding 3 months. The age and body mass index (BMI) of the patients were $21.6 \pm 4.8$ years and $26.4 \pm 5.1 \mathrm{~kg} / \mathrm{m}^{2}$ (means \pm S.D.) respectively. The control group consisted of 11 healthy women with regular menstrual cycles (28-33 days), $27.5 \pm 3.5$ years old, with BMI $22.3 \pm$ $3.0 \mathrm{~kg} / \mathrm{m}^{2}$ who also had not used oral contraceptives for at least the preceding 3 months, and who were without either clinical or laboratory signs of hyperandrogenaemia. The controls were recruited from among the healthcare personnel of the Institute of Endocrinology in Prague and their acquaintances.

\section{Study protocol}

The local ethics committee of the Institute of Endocrinology approved the protocol for the study. The patients were evaluated in the clinical department of the Institute of Endocrinology as outpatients, and after signing written informed consent underwent the following three tests in the early follicular phase of the same menstrual cycle (1st to 6 th days).

ACTH test Synacthen (250 $\mu \mathrm{g}$; CIBA-Geigy, Basel, Switzerland) was given i.m. between 0730 and $0830 \mathrm{~h}$. Basal blood samples and samples withdrawn at 30 and $60 \mathrm{~min}$ were taken for the determination of testosterone, androstenedione, dehydroepiandrosterone (DHEA), DHEAS, 17-hydroxyprogesterone (170HP), 17-hydroxypregnenolone (170HPl) and cortisol.

GnRHa test Buserelin (100 $\mu \mathrm{g}$; Suprefact; Hoechst Marion Roussel GmBh, Wein, Austria) was given s.c. after pretreatment with $2 \mathrm{mg}$ dexamethasone at $2200 \mathrm{~h}$ the night before. Blood samples were collected between 0730 and $0800 \mathrm{~h}$ (basal), and after 4 and $24 \mathrm{~h}$. The concentrations of testosterone, androstenedione, DHEA, oestradiol (E2), 170HP, 17OHPl, SHBG, cortisol and LH were measured in all the samples.

oGTT with dextrose (75 g) After overnight fasting, blood samples were withdrawn for the determination of glucose, insulin and $\mathrm{C}$ peptide before drug administration, and then again after 30, 60, 120 and $180 \mathrm{~min}$. Proinsulin (PI) was determined at 0,30 and $180 \mathrm{~min}$.

After the tests, the treatment started with metformin (Siofor Berlin Chemie) at $500 \mathrm{mg}$ daily for 1 week. As the tolerance was good in all cases, the dose was increased to $1000 \mathrm{mg}$ per day. This dose was chosen to minimize the possible side-effects of metformin. Patients were advised to follow an isocaloric diet during the study. After completing the course of treatment $(27 \pm 4$ weeks), all the tests mentioned above were performed again in the same order. The pattern of the menstrual cycle was defined as follows: secondary amenorrhoea absence of menstruation for 180 days or more; oligomenorrhoea - average length of the cycle between 42 and 180 days; regular cycle - average length of the cycle between 22 and 41 days, with no more than a 5-day variation from one cycle to another.

\section{Laboratory assays}

C peptide was measured by immunoradiometric assay (IRMA) kit from Immunotech (Marseilles, France). The cross-reactivity of antiserum with both insulin and glucagon was less than $0.05 \%$. Glucose was evaluated in venous plasma (glucoso-oxidase method; Beckmann analyzer, Fullerton, CA, USA). Insulin was estimated by IRMA kit from Immunotech. PI was determined using an enzyme-linked immunosorbent assay (ELISA) kit 
(IBL, Hamburg, Germany), with no cross-reactivity with insulin and with $\mathrm{C}$ peptide. DHEA and DHEAS were measured using radioimmunoassay (RIA) kits from Immunotech. DHEA was measured in diethylether extracts, while DHEAS was determined directly in serum. Testosterone was determined by standard RIA using anti-testosterone-3-carboxymethyloxime:bovine serum albumin (BSA) antiserum and testosterone-3carboxymethyloxime-tyrosylmethylester- $\left[{ }^{125} \mathrm{I}\right]$ as a tracer; the intra-assay and interassay coefficients of variation (CV values) were $7.2 \%$ and $10 \%$ respectively, and the sensitivity was $0.21 \mathrm{nmol} / \mathrm{l}$. Androstenedione was determined using a standard RIA with antiandrostenedione-6-carboxymethyloxime:BSA antiserum and $\left[{ }^{3} \mathrm{H}\right]$ androstenedione as a tracer; the intra-assay and interassay $\mathrm{CV}$ values were $8.1 \%$ and $10.2 \%$ respectively, and the sensitivity was $0.39 \mathrm{nmol} / \mathrm{l}$. 17OHPl was measured using a method published elsewhere (24). 17OHP, LH and follicle-stimulating hormone were measured by RIA kits from Immunotech. E2 was measured by the RIA kit from Immunotech. SHBG was estimated using the IRMA method (Orion, Espoo, Finland). Cortisol was measured by standard RIA using anti-cortisol-3-carboxymethyloxime:BSA antiserum and cortisol-3-carboxymethyloxime-TME- $\left[{ }^{125} \mathrm{I}\right]$ as a tracer; intra-assay and interassay $\mathrm{CV}$ values were $5.2 \%$ and $7.6 \%$ respectively, and the sensitivity was $12.3 \mathrm{nmol} / \mathrm{l}$.

\section{Computations}

To evaluate the changes in adrenal and ovarian activity of enzymes acting in steroid metabolism, product/ precursor ratios of the basal steroid levels and absolute levels after stimulation by ACTH or by GnRHa buserelin was employed. Considering the insignificance of the changes in steroid basal values after metformin treatment we used absolute values after ACTH stimulation instead of the differences between basal and stimulated values to avoid the inclusion of superfluous unexplained variability to statistical analysis. Androstenedione/DHEA and $170 \mathrm{HP} / 17 \mathrm{OHPl}$ were used as indices of $3 \beta$-hydroxysteroid dehydrogenase (3$\beta$-HSD) in $\mathrm{C}_{19}$ and $\mathrm{C}_{21}$ steroids respectively. Similarly, the androstenedione/170HP and DHEA/170HPl ratio was employed as an index of C17,20-lyase activity in the $\Delta^{4}$ and $\Delta^{5}$ pathways respectively. The testosterone/androstenedione ratio was used as an index of $17 \beta$ hydroxysteroid dehydrogenase (17 $\beta$-HSD), and the E2/testosterone ratio as an index of aromatase (AR) activity. The DHEA/DHEAS ratio was used for the evaluation of the changes in equlibrium between DHEA and DHEAS. The index of free testosterone was calculated as $100 \times$ testosterone/SHBG. For evaluation of insulin secretion and insulin resistance, HOMA indices were employed (HOMA-R for insulin resistance and HOMA-F for $\beta$ cell function), as reported by Matthews et al. (25). Good correlations were found with insulin sensitivity determined by euglycaemic clamp as a gold standard (25). The validation of insulin secretion was acceptable (26). The basal C protein/ insulin molar ratio was used to evaluate the hepatic extraction of insulin.

\section{Statistical treatment of the data}

Two-way ANOVA was used for the evaluation of changes in the steroids and in the indices of enzyme activity. The treatment (before treatment, after treatment) and the time of the appropriate test were the first and second factor respectively. To attain an approximately Gaussian distribution of the data, which is a prerequisite for a correct ANOVA test, the variables were treated by logarithmic or power transformation to minimum skewness and the mean values within lower and upper limits of 95\% CI values were retransformed to the original scale. For the evaluation of the change after metformin treatment within the individual stages of a dynamic test, Wilcoxon's paired test was used, because of the mostly non-Gaussian distribution of the data. Wilcoxon's paired test was also used to evaluate changes in HOMA-R, HOMA-F and BMI. The MannWhitney U test was used to compare the patients with the healthy control group. Null hypotheses of statistical test were evaluated on the $95 \%$ level of significance $(P<0.05)$.

\section{Results \\ Clinical observations}

The basal clinical characteristics and steroid levels for both the healthy controls and the patients with PCOS are given in Table 1 . The mean age of the healthy controls was significantly higher $(P=0.003)$ than that of the PCOS patients. A tendency towards a higher mean BMI in the PCOS patients was found, but this tendency did not attain statistical significance.

After treatment with metformin, no significant change in BMI was observed (from 25.9 \pm 5.9 to $25.5 \pm 5.4 \mathrm{~kg} / \mathrm{m}^{2}$; means \pm s.D.). In 14 women (58\%), there was a marked improvement of regularity in the menstrual cycle, defined either as resolution of secondary amenorrhoea or as a shortening of the average length of cycles to 35 or less days. In nine women $(37.5 \%)$, there was no change in the average length of cycles. In one patient, secondary amenorrhoea developed during the treatment. In the group with the improved cycle, in eight patients the cycle during treatment was regular. Of these eight patients, two had suffered with secondary amenorrhoea and six with oligomenorrhoea before treatment. The rest of the group with improvement of the cycle (six patients) continued to exhibit irregular cycles despite the treatment; however, the length of the cycle was considerably shifted towards a normal duration. In 
Table 1 Basal steroid values in patients with PCOS and healthy controls. Values are means \pm S.D.

\begin{tabular}{lccc}
\hline Variable & $\begin{array}{c}\text { Women with PCOS } \\
(n=24)\end{array}$ & $\begin{array}{c}\text { Healthy controls } \\
(n=11)\end{array}$ & $\boldsymbol{P}$ \\
\hline Age & $21.6 \pm 4.8$ & $27.5 \pm 3.5$ & $<0.004$ \\
BMI & $26.4 \pm 5.1$ & $22.3 \pm 3.0$ & $\mathrm{NS}$ \\
Cortisol $(\mathrm{nmol} / \mathrm{l})$ & $454 \pm 204$ & $420 \pm 123$ & $\mathrm{NS}$ \\
Testosterone $(\mathrm{nmol} / \mathrm{l})$ & $2.35 \pm 0.95$ & $1.75 \pm 0.49$ & $\mathrm{NS}$ \\
SHBG (nmol/l) & $24.5 \pm 8.8$ & $54.7 \pm 22.0$ & $<0.007$ \\
Index of free testosterone & $10.80 \pm 5.25$ & $4.11 \pm 2.72$ & $\mathrm{NS}$ \\
Androstenedione (nmol/l) & $5.4 \pm 2.4$ & $4.10 \pm 1.77$ & $<0.01$ \\
DHEA-S ( $\mu$ mol/l) & $8.08 \pm 3.0$ & $5.44 \pm 2.08$ & $\mathrm{NS}$ \\
DHEA (nmol/l) & $27.6 \pm 13.8$ & $19.6 \pm 7.3$ & $\mathrm{NS}$ \\
17-OHP (nmol/l) & $2.16 \pm 1.32$ & $1.59 \pm 1.19$ & $\mathrm{NS}$ \\
17-OHPI (nmol/l) & $13.2 \pm 12.55$ & $6.51 \pm 5.31$ & \\
& & & \\
\hline
\end{tabular}

NS, not significant.

two of these patients, secondary amenorrhoea and in four patients oligomenorrhoea was found before the therapy. In the group of nine women with no change in the pattern of the cycle after therapy, in two cases secondary amenorrhoea, in four cases oligomenorrhoea and in two cases regular cycles were found before the treatment period. The last woman from this group with oligomenorrhoea underwent insertion of an intrauterine device during the treatment with metformin.

\section{Basal steroid values}

No significant differences in the levels of DHEA, DHEAS, 170HP, 170HPl and testosterone before and after treatment with metformin were found. Only the elevations of basal cortisol $(P<0.07$, Wilcoxon's paired test $)$ and androstenedione $(P<0.06$, Wilcoxon's paired test) levels after metformin treatment approached statistical significance (Fig. 1). An insignificant increasing tendency in the levels of SHBG (from $24.8 \pm 9.0$ to $30.4 \pm 15.7 \mathrm{nmol} / \mathrm{l}$ ) was observed.

\section{Adrenal activity (ACTH test)}

No significant differences were found between the absolute stimulated values of cortisol, DHEA, DHEAS, $17 \mathrm{OHP}, 17 \mathrm{OHPl}$, androstenedione and testosterone before and after treatment with metformin (Fig. 1). Nevertheless, when the enzyme activities were tested (Fig. 2) a significant decrease was detected in the stimulated activity of $3 \beta$-HSD in $\mathrm{C}_{21}$ steroids $(P<0.05$, F-test, ANOVA). In addition, an increase in the activity of $\mathrm{C} 17,20$-lyase in the $\Delta^{4}$ pathway $(P<0.01$, F-test, ANOVA $)$ was noted. A significant decrease in the activity of $17 \beta-H S D$ was found $(P<0.01$, F-test, ANOVA), while no changes were observed in the activity of $3 \beta$-HSD in $\mathrm{C}_{19}$ steroids and C17,20-lyase in the $\Delta^{5}$ pathway. Finally, a significant growth in the DHEA/DHEAS ratio was found after metformin treatment $(P<0.05$, F-test, ANOVA), particularly at the 60th minute of ACTH test values, where the difference was again detected by means of Wilcoxon's paired test $(P<0.05)$. No significant changes were observed in the stimulated activities of $3 \beta$-HSD in $C_{21}$ steroids and in C17,20-lyase in the $\Delta^{4}$ pathway (results not shown).

\section{Ovarian activity (GnRHa test with buserelin)}

Significant decreases in the stimulated absolute levels of testosterone $(P<0.05$, F-test, ANOVA), free testosterone index $(P<0.01$, F-test, ANOVA $)$, LH $(P<0.05$, F-test, ANOVA) and E2 ( $P<0.01$, F-test, ANOVA), and an increase in the levels of $170 \mathrm{HPl}(P<0.05$, F-test, ANOVA) were detected. No significant changes were found in the absolute concentrations of SHBG, 17OHP, DHEA, DHEAS and androstenedione (Fig. 3). In the indices of enzyme activities (Fig. 4), statistically significant decreases were observed in $3 \beta$-HSD in $C_{21}$ steroids $(P<0.01$, F-test, ANOVA), in C17,20-lyase in the $\Delta^{5}$ pathway $(P<0.01)$ and in $17 \beta-H S D$ $(P<0.05$, F-test, ANOVA). The decrease in AR activity at the 24th hour of the buserelin test after metformin treatment was close to statistical significance ( $P<0.054$, Wilcoxon's paired test). No change was found in either $3 \beta$-HSD activity in $C_{19}$ steroids or on C17,20-lyase activity in the $\Delta^{4}$ pathway (results not shown).

\section{Glucose tolerance (oGTT)}

All of the patients but one initially had normal glucose tolerance as defined by the American Diabetes Association/World Health Organization criteria. After metformin treatment, the changes in PI and insulin were not significant: in insulin, from $11.57(7.1 ; 18.0) \mu \mathrm{IU} / \mathrm{l}$ to $8.6(5.1 ; 13.7) \mu \mathrm{IU} / \mathrm{l}$ (values are given as means; lower limit of $95 \%$ CI, upper limit of $95 \%$ CI). A significant elevation of stimulated $\mathrm{C}$ peptide levels in the 120th min (from $2.47(2.11 ; 2.87) \mathrm{nmol} / \mathrm{l}$ to $3.43(2.96$; 3.94) nmol/l) after treatment was found $(P<0.01$, F-test, ANOVA). Changes in the insulin/PI ratios were 


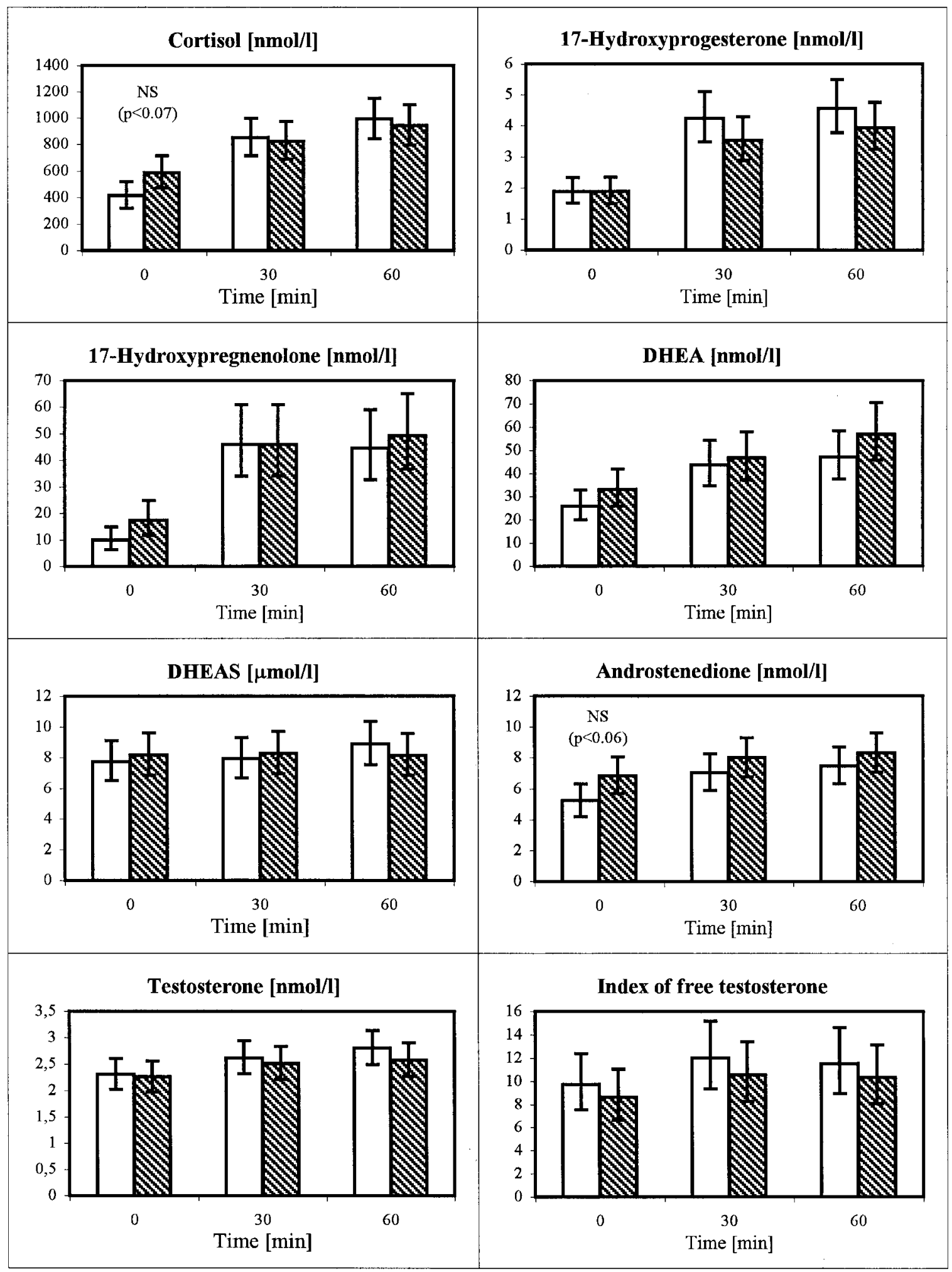

Figure 1 Steroid changes and the index of free testosterone after metformin treatment in the ACTH test. Empty and hatched columns represent the retransformed mean values before and after treatment respectively. Vertical lines denote $95 \% \mathrm{Cl}$ values of retransformed mean values. Significance was evaluated by two-way ANOVA with treatment and ACTH test stage as the first and second factors respectively. 


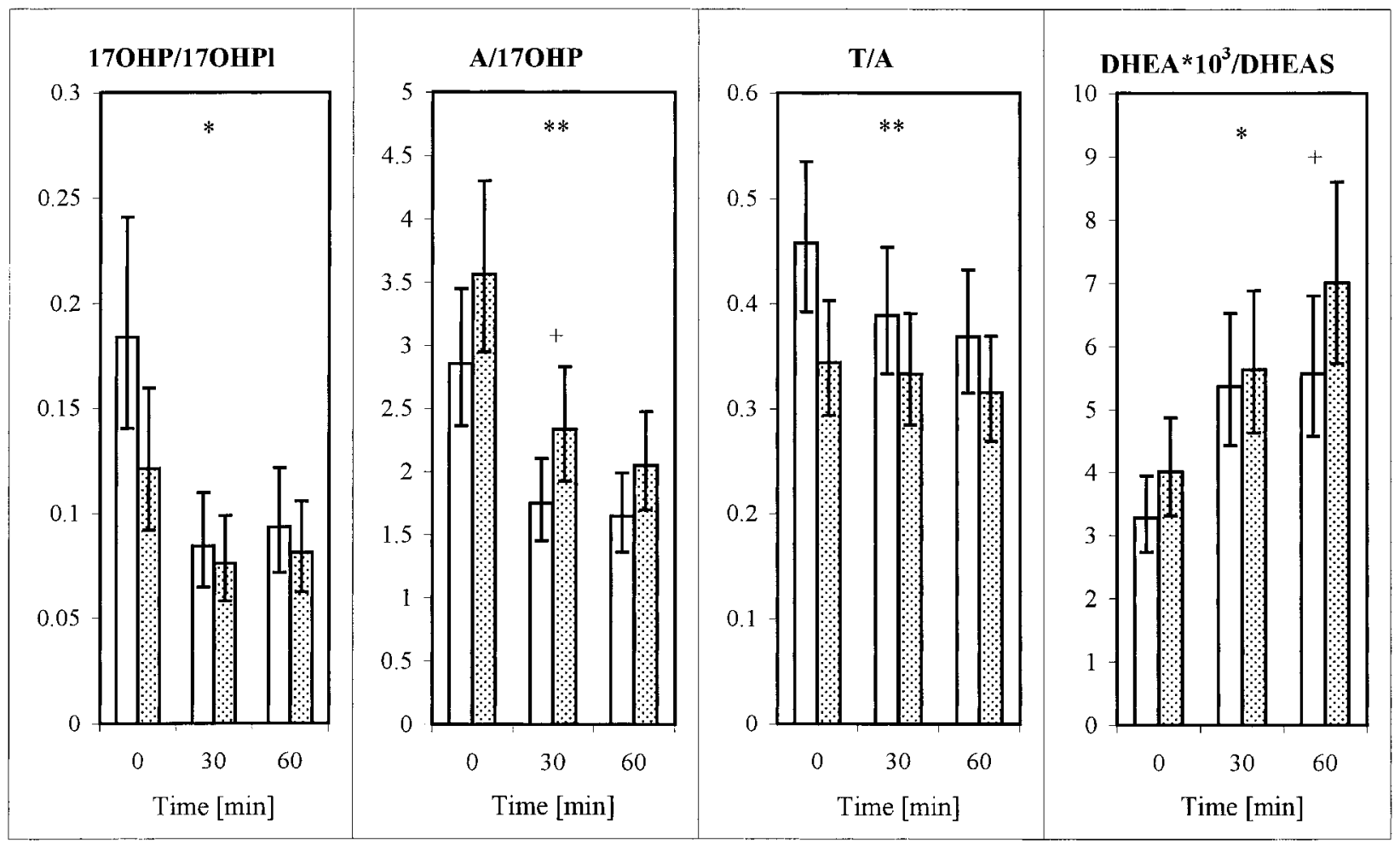

Figure 2 Changes in adrenal enzyme activity after metformin treatment in the ACTH test. Empty and stippled columns represent the retransformed mean values before and after treatment respectively. Vertical lines denote $95 \% \mathrm{Cl}$ values of retransformed mean values. Significance was evaluated by two-way ANOVA with treatment and ACTH test stage as the first and second factors respectively. ${ }^{\star} P<0.05,{ }^{* *} P<0.01$, significance of the change after treatment with metformin within the ACTH test as a whole. ${ }^{+} P<0.05$, significance of the change after treatment with metformin in the individual stages of the ACTH test. A, androstenedione; T, testosterone.

insignificant using ANOVA except significantly reduced values in the basal insulin/PI ratio after metformin treatment (from $6.72(4.81 ; 9.2)$ to $4.1(2.87 ; 5.69)$, $P<0.05$, Wilcoxon's paired test). Changes in the basal $C$ peptide/insulin molar ratios were insignificant using ANOVA, albeit a trend towards an increase could be seen (from $11.15(8.36$; 15.35) to 15.35 (11.15; 19.34)). No significant change was detected either in blood glucose or in insulin/glucose and PI/glucose ratios (not shown). No significant changes were observed after metformin treatment in either of the HOMA indices, although a trend towards a decline in HOMA-R was detected (from $2.31(1.82 ; 2.92)$ to 1.60 $(1.26 ; 2.03))$.

\section{Discussion}

The aim of this study was to investigate changes in basal steroid levels and stimulated adrenal and ovarian steroidogenesis after metformin treatment in women with PCOS. To define PCOS, the broader definition proposed by the NIH consensus in 1990 was used chronic anovulation and hyperandrogenaemia. Our group under study consisted of young, only mildly obese patients with normal glucose tolerance.

The healthy controls were significantly older than the subjects, but this difference probably has no biological importance in this situation, as both groups were between 20 and 30 years of age.

In nearly two thirds of patients a marked improvement in the menstrual cycle pattern was seen. No significant change was found in basal steroid levels after metformin treatment; only basal cortisol and androstenedione levels displayed a tendency towards higher values. In not finding a change in the basal levels of testosterone, free testosterone or androstenedione after metformin treatment, this study therefore accords with the results obtained by some authors (19,

Figure 3 Steroid changes and the index of free testosterone after metformin treatment in the buserelin test. Empty and hatched columns represent the retransformed mean values before and after treatment respectively. Vertical lines denote $95 \% \mathrm{Cl}$ values of retransformed mean values. ${ }^{\star} P<0.05,{ }^{\star \star} P<0.01$, significance of the change after treatment with metformin in the buserelin test as a whole. Significance was evaluated by two-way ANOVA with treatment and buserelin test stage as the first and second factors respectively. ${ }^{+} P<0.05,{ }^{+++} P<0.001$, significance of the change after treatment with metformin in the individual stages of the buserelin test. 


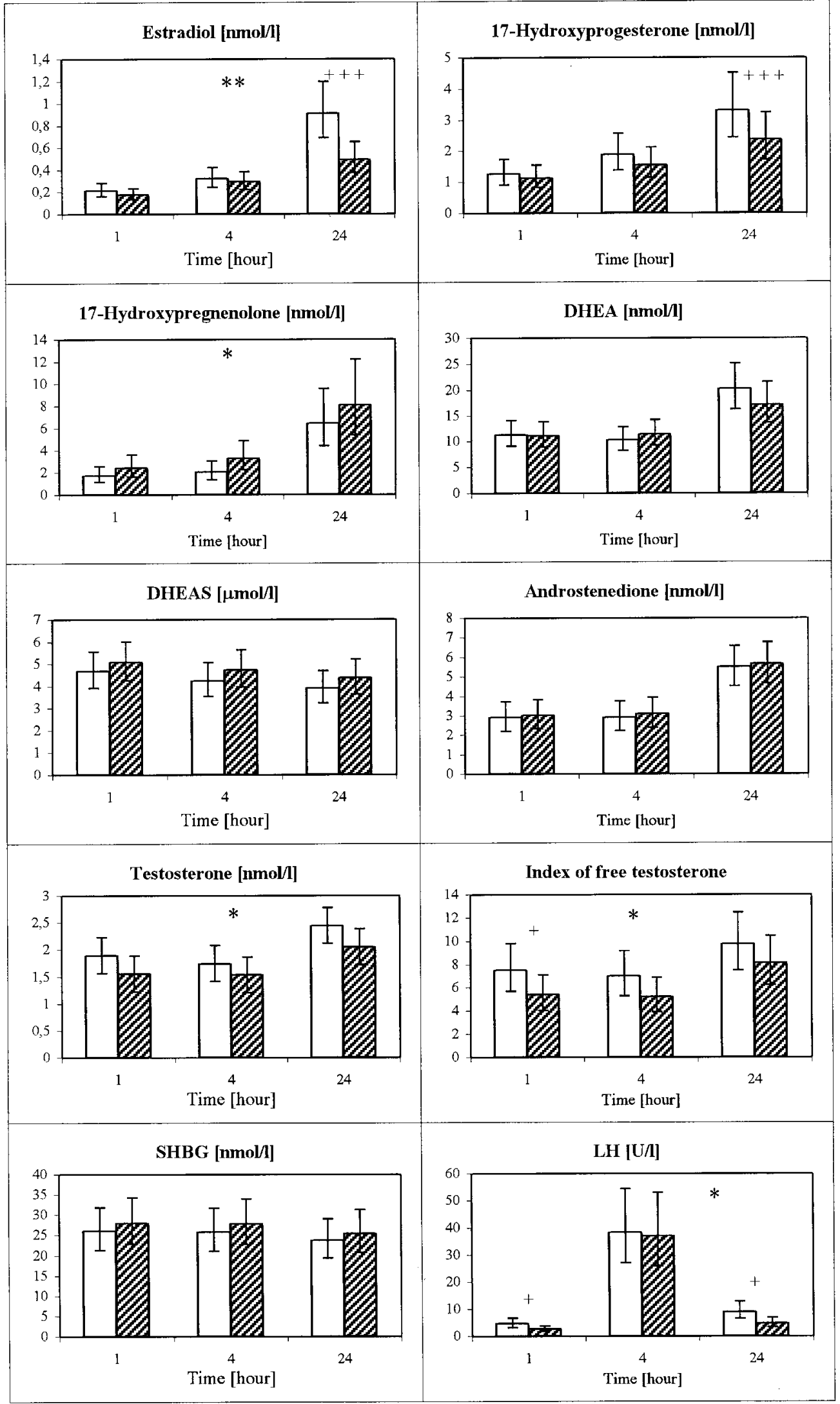




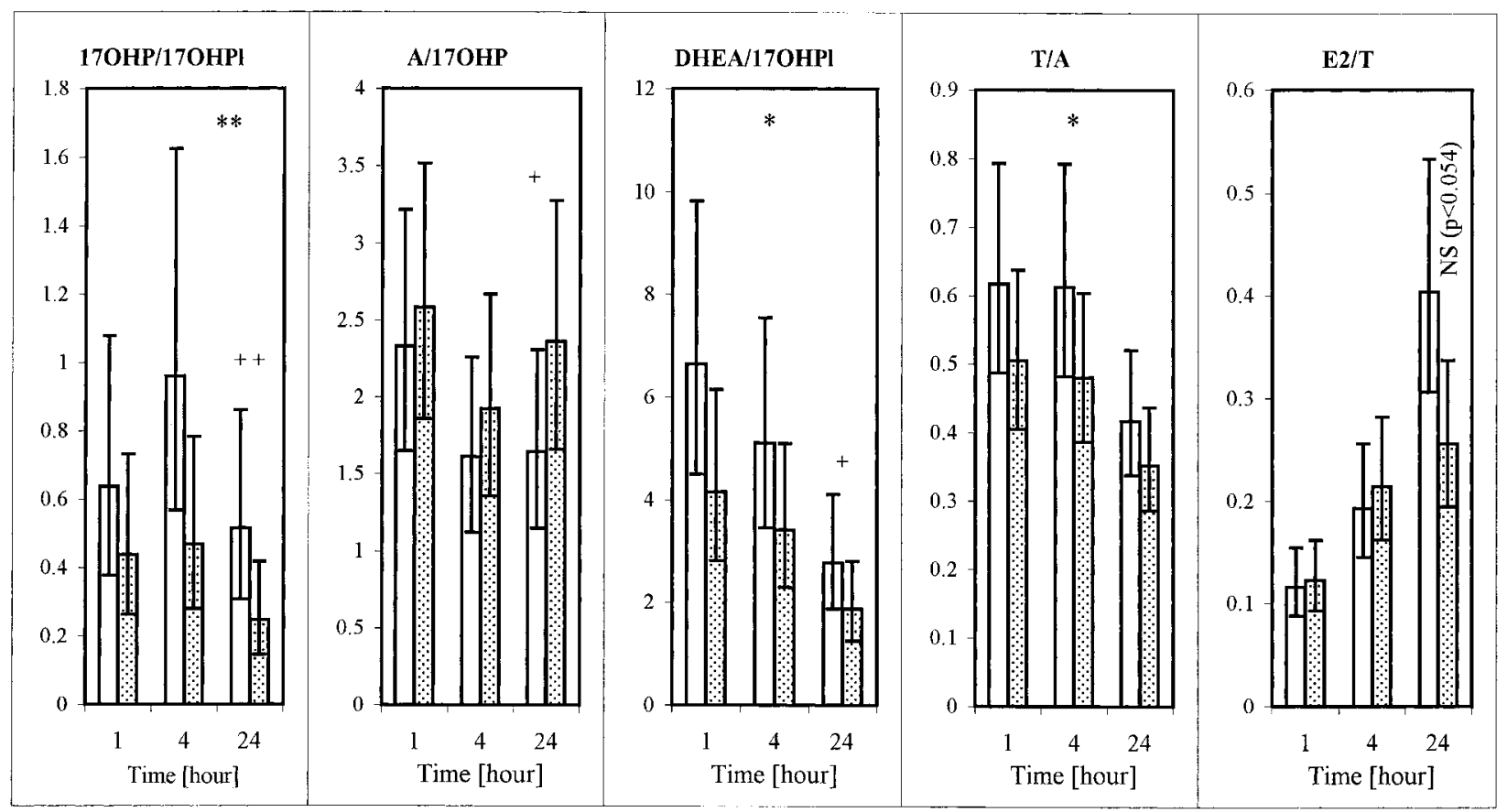

Figure 4 Changes in ovarian enzyme activity after metformin treatment in the buserelin test. Empty and dotted columns represent the retransformed mean values before and after treatment respectively. Vertical lines denote $95 \% \mathrm{Cl}$ values of retransformed mean values. Significance was evaluated by two-way ANOVA with treatment and the buserelin test stage as the first and second factors respectively. ${ }^{*} P<0.05,{ }^{* \star} P<0.01$, significance of the change after treatment with metformin in the buserelin test as a whole. ${ }^{+} P<0.05$, ${ }^{++} P<0.001$, significance of the change after treatment with metformin in the individual stages of the buserelin test. A, androstenedione; $\mathrm{T}$, testosterone.

20), although not with those obtained by others (1215). Most of these studies found a decrease only in free testosterone, without concomitant changes in other androgens. This may be explained by an elevation of SHBG after metformin treatment (possibly via reduction of hepatic insulin resistance). Duration of treatment and the dose of metformin can probably play a role. Only a few studies in PCOS $(15,18,19,27-29)$ lasted for 6 months or longer, and in one (19) the significant fall in androgen levels was found only after 6 weeks but not after 6 months of treatment.

As a next step, evaluation of enzymatic activities after stimulation of the adrenals and ovaries was attempted. Basal levels of androgens are the product of both ovaries and adrenals and it is difficult to distinguish the source of hormonal disturbance. PCOS is commonly connected with ovarian overproduction of $17 \mathrm{OHP}$ and androstenedione and with hypersecretion of these steroids after GnRHa challenge (3). In addition, an adrenal steroid excess with hypersecretion of androstenedione and DHEA after ACTH is frequently found in PCOS. The elevation of ACTH-stimulated enzymatic activities was not always connected with the elevation of these activities in the basal state (30). As the lowering of androgens is not equivocally found after metformin, we supposed that this observation could be due to more subtle effects of metformin on the stimulated steroid secretion (maybe not necessarily reflected by the lowering of basal levels).

The manifestation of the changes in enzyme activity on the steroidogenic pathways was more pronounced after challenge with trophic hormones compared with the basal values.

We are aware of only two studies concerning the effects of metformin on adrenal steroidogenesis in women with PCOS, with discrepant results. After 1 month of metformin treatment, la Marca et al. (11) found a significant reduction in the maximum increment and area under the curve of $17 \mathrm{OHP}$, androstenedione, testosterone and free testosterone after ACTH stimulation, and decreases in the 170HP/progesterone ratio (an index of $\mathrm{C} 17$ hydroxylase activity) and androstenedione/170HP ratio (an index of the activity of $\mathrm{C} 17,20$ lyase in the $\Delta 4$ pathway). On the other hand, Unluhizarci et al. (10) found no difference in 170HP or androstenedione response after ACTH stimulation, after a 3-month course of metformin. In our study, no significant changes in their absolute values were found, in terms of ACTH-stimulated steroid levels after metformin treatment. However, examination of enzymatic activities defined as product/precursor ratios revealed a significant decrease in the stimulated 
activity of $3 \beta-\mathrm{HSD}$ in $\mathrm{C}_{21}$ steroids, an increase in the activity of $\mathrm{C} 17,20$-lyase in the $\Delta 4$ pathway and a significant decrease in the activity of $17 \beta-H S D$.

The finding of increased C17,20-lyase activity in the $\Delta 4$ pathway was surprising. It contradicts a study (11) which found a decrease in its activity after metformin treatment. Unfortunately, it was not possible to examine the activity of $\mathrm{C} 17,20$ hydroxylase in both $(\Delta 4$ and $\Delta 5$ ) pathways. It cannot be excluded that such activity decreases, leading in turn to a decreased concentration of $170 \mathrm{HP}$. This situation might then be interpreted as an increase in the activity of the next enzymatic step (lyase). A decrease in 17 $\beta$-HSD activity leads to a decrease in testosterone production (as the most active androgen).

There was a tendency towards lower levels of DHEAS after metformin treatment, not reaching statistical significance. A significant increase was then found in the DHEA/DHEAS ratio. This might be due either to the lower synthesis of DHEAS or to changes in the interconversion of these two steroids. A recently published study (16) has described a decline in DHEAS after metformin only in a subgroup of patients with high basal DHEAS. This subgroup also had a better clinical outcome (defined as an improvement in the length of the menstrual cycle) than in the subgroup with initially normal DHEAS.

With regard to ovarian steroid production, significant reductions in stimulated levels of $17 \mathrm{OHP}$, testosterone, the index of free testosterone, E2 and LH were found. These findings again accord with some studies $(12-14,18)$ but not with others $(20,30)$. In steroid enzyme activities, decreases in the stimulated activity of $3 \beta$-HSD in $C_{21}$ steroids, in the activity of $C 17,20$-lyase in the $\Delta 5$ pathway, in $17 \beta-H S D$ and in androstenedione activity were found.

Examining glycide metabolism by oGTT, we found a significant increase in the stimulated $\mathrm{C}$ peptide levels, without significant changes in either glucose levels or insulinaemia, and without significant change in the basal $\mathrm{C}$ peptide/insulin ratio (as an index of hepatic insulin clearance). In the literature, information is scarce regarding $\mathrm{C}$ peptide secretion after metformin treatment in groups of patients with normal glucose tolerance and insulin resistance (as women with PCOS mostly have). We are aware of a study (31) finding no change in either basal or stimulated levels of $C$ peptide in a group of hypertensive patients after metformin. In a group of obese type 2 diabetics an increase in $\mathrm{C}$ peptide levels after metformin treatment was found (32). These discrepancies are difficult to explain and deserve further research. In this study, no significant changes were found in HOMA-R and fasting insulin, as commonly used indices of insulin resistance, or in HOMA-F as an index of insulin secretion. Nevertheless, a slight tendency to reduction in fasting insulinaemia and HOMA-R was seen. The gold standard for estimate of insulin resistance is the euglycaemic clamp. To our knowledge, there have been only a few studies using the clamp in PCOS women under metformin treatment $(15,18)$. In the study of Diamanti-Kandarakis et al. (15), an increase in insulin sensitivity after metformin not accompanied by a significant decrease in fasting insulin was reported. Several studies were conducted with metformin in type 2 diabetic patients $(33,34)$. These studies reported a relatively small improvement in peripheral insulin sensitivity and the authors suggested the suppression of endogenous hepatic glucose production as the primary mechanism of metformin action. Concerning the hyperbolic relationship of fasting insulin and insulin sensitivity (35), we suggest that the relatively small improvement in insulin sensitivity cannot induce an apparent fall in fasting insulin that could reach statistical significance. The same probably holds for HOMA-R as it is derived from basal insulinaemia. Another mechanism responsible for the fall in basal insulin levels is the improvement in hepatic insulin clearance. As previously, we observed only a small improvement. Other studies dealing with PCOS and finding a significant decrease in fasting insulin levels almost invariably involved women with an average BMI between 27 and $36 \mathrm{~kg} / \mathrm{m}^{2}(10,16,18$, 19, 27). Moreover, the degree of hyperinsulinaemia in these studies was greater than in our patients.

In conclusion, the following can be stated. (1) Nearly two thirds $(58 \%)$ of the patients reported an improvement in the regularity of their menstrual cycle, and only in one patient did the menstrual pattern worsen during treatment. (2) The long-term course of metformin treatment in women with PCOS reduced activity in several of the metabolic pathway enzymes responsible for androgen production in both the ovaries and the adrenals. (3) The methods used to detect insulin resistance (HOMA model and basal insulin) did not discover a significant improvement after metformin treatment; nevertheless, a reduction in insulin resistance after metformin cannot be excluded - using more sophisticated methods of detection. (4) Metformin is a clinically useful drug in the treatment of PCOS (even at the dose of $1000 \mathrm{mg} /$ day), with good tolerance.

\section{Acknowledgements}

This work was supported by research grants nos 48473, 6702 and 5398-3 of the Internal Grant Agency of the Czech Ministry of Health, and by research design no. 000000023761 of the Institute of Endocrinology in Prague.

\section{References}

1 Franks S, Gilling-Smith C, Watson H \& Willis D. Insulin action in the normal and polycystic ovary. Endocrinology and Metabolism Clinics of North America 199928 361-378.

2 Nestler JE, Powers LP, Matt DW, Steingold KA, Plymate SR, Rittmaster RS et al. A direct effect of hyperinsulinemia on serum sex hormone-binding globulin levels in obese women with the 
polycystic ovary syndrome. Journal of Clinical Endocrinology and Metabolism 199172 83-89.

3 Ehrmann DA, Barnes RB \& Rosenfield RL. Polycystic ovary syndrome as a form of functional ovarian hyperandrogenism due to dysregulation of androgen secretion. Endocrine Reviews 1995 $16322-353$.

4 Moghetti P, Castello R, Negri C, Tosi F, Spiazzi GG, Brun E et al. Insulin infusion amplifies 17 alpha-hydroxycorticosteroid intermediates response to adrenocorticotropin in hyperandrogenic women: apparent relative impairment of 17,20-lyase activity. Journal of Clinical Endocrinology and Metabolism 1996 81 881-886.

5 Ditkoff EC, Fruzzetti F, Chang L, Stancyzk FZ \& Lobo RA. The impact of estrogen on adrenal androgen sensitivity and secretion in polycystic ovary syndrome. Journal of Clinical Endocrinology and Metabolism $1995 \mathbf{8 0} 603-607$.

6 Carmina E, Gonzalez F, Vidali A, Stanczyk FZ, Ferin M \& Lobo RA. The contributions of oestrogen and growth factors to increased adrenal androgen secretion in polycystic ovary syndrome. Human Reproduction 199914 307-311.

7 Stanczyk FZ, Chang L, Carmina E, Putz Z \& Lobo RA. Is 11 betahydroxyandrostenedione a better marker of adrenal androgen excess than dehydroepiandrosterone sulfate? American Journal of Obstetrics and Gynecology 1991165 1837-1842.

8 Bailey CJ. Biguanides and NIDDM. Diabetes Care $199215755-$ 772.

9 Mansfield R, Galea R, Brincat M \& Mason H. Metformin has direct effects on human ovarian steroidogenesis. Journal of Endocrinology 2000164 (Suppl) P266.

10 Unluhizarci K, Kelestimur F, Sahin Y \& Bayram F. The treatment of insulin resistance does not improve adrenal cytochrome P450c17alpha enzyme dysregulation in polycystic ovary syndrome. European Journal of Endocrinology 1999140 56-61.

11 la Marca A, Morgante G, Paglia T, Ciotta L, Cianci A \& De Leo V. Effects of metformin on adrenal steroidogenesis in women with polycystic ovary syndrome. Fertility and Sterility 199972 985989 (published erratum appears in Fertility and Sterility 200073 874).

12 Nestler JE \& Jakubowicz DJ. Decreases in ovarian cytochrome P450c17 alpha activity and serum free testosterone after reduction of insulin secretion in polycystic ovary syndrome (see comments). New England Journal of Medicine 1996335 617-623.

13 Velazquez EM, Mendoza S, Hamer T, Sosa F \& Glueck CJ. Metformin therapy in polycystic ovary syndrome reduces hyperinsulinemia, insulin resistance, hyperandrogenemia, and systolic blood pressure, while facilitating normal menses and pregnancy. Metabolism 199443 647-654.

14 Nestler JE \& Jakubowicz DJ. Lean women with polycystic ovary syndrome respond to insulin reduction with decreases in ovarian P450c17 alpha activity and serum androgens. Journal of Clinical Endocrinology and Metabolism 199782 4075-4079.

15 Diamanti-Kandarakis E, Kouli C, Tsianateli T \& Bergiele A. Therapeutic effects of metformin on insulin resistance and hyperandrogenism in polycystic ovary syndrome (see comments). European Journal of Endocrinology 1998138 269-274.

16 Kolodziejczyk B, Duleba AJ, Spaczynski RZ \& Pawelczyk L. Metformin therapy decreases hyperandrogenism and hyperinsulinemia in women with polycystic ovary syndrome. Fertility and Sterility 200073 1149-1154.

17 la Marca A, Egbe TO, Morgante G, Paglia T, Cianci A, De Leo V et al. Metformin treatment reduces ovarian cytochrome P-450c17alpha response to human chorionic gonadotrophin in women with insulin resistance-related polycystic ovary syndrome. Human Reproduction 200015 21-23 (published erratum appears in Human Reproduction 200015 736).

18 Moghetti P, Castello R, Negri C, Tosi F, Perrone F, Caputo M et al. Metformin effects on clinical features, endocrine and metabolic profiles, and insulin sensitivity in polycystic ovary syndrome: a randomized, double-blind, placebo-controlled 6-month trial, followed by open, long-term clinical evaluation. Journal of Clinical Endocrinology and Metabolism 200085 139-146.
19 Morin-Papunen LC, Koivunen RM, Ruokonen A \& Martikainen HK. Metformin therapy improves the menstrual pattern with minimal endocrine and metabolic effects in women with polycystic ovary syndrome. Fertility and Sterility 199869 691-696.

20 Ehrmann DA, Cavaghan MK, Imperial J, Sturis J, Rosenfield RL \& Polonsky KS. Effects of metformin on insulin secretion, insulin action, and ovarian steroidogenesis in women with polycystic ovary syndrome. Journal of Clinical Endocrinology and Metabolism 199782 524-530.

21 Acbay O \& Gundogdu S. Can metformin reduce insulin resistance in polycystic ovary syndrome? Fertility and Sterility 199665 946-949.

22 Dunaif A. Insulin resistance and the polycystic ovary syndrome: mechanism and implications for pathogenesis. Endocrine Reviews $199718774-800$.

23 Adams J, Franks S, Polson DW, Mason HD, Abdulwahid N, Tucker $\mathrm{M}$ et al. Multifollicular ovaries: clinical and endocrine features and response to pulsatile gonadotropin releasing hormone. Lancet 1985 ii $1375-1379$.

24 Hill M, Lukac D, Lapcik O, Sulcova J, Hampl R, Pouzar V et al. Age relationships and sex differences in serum levels of pregnenolone and 17-hydroxypregnenolone in healthy subjects. Clinical Chemistry and Laboratory Medicine 199937 439-447.

25 Matthews DR, Hosker JP, Rudenski AS, Naylor BA, Treacher DF \& Turner RC. Homeostasis model assessment: insulin resistance and beta-cell function from fasting plasma glucose and insulin concentrations in man. Diabetologia 198528 412-419.

26 Haffner SM, Miettinen H \& Stern MP. The homeostasis model in the San Antonio Heart Study. Diabetes Care 199720 1087-1092.

27 Glueck CJ, Wang P, Fontaine R, Tracy T \& Sieve-Smith L. Metformin-induced resumption of normal menses in 39 of 43 (91\%) previously amenorrheic women with the polycystic ovary syndrome. Metabolism $1999 \mathbf{4 8}$ 511-519.

28 Velazquez EM, Mendoza SG, Wang P \& Glueck CJ. Metformin therapy is associated with a decrease in plasma plasminogen activator inhibitor-1, lipoprotein(a), and immunoreactive insulin levels in patients with the polycystic ovary syndrome. Metabolism $199746454-457$.

29 Azziz R, Black V, Hines GA, Fox LM \& Boots LR. Adrenal androgen excess in the polycystic ovary syndrome: sensitivity and responsivity of the hypothalamic-pituitary-adrenal axis. Journal of Clinical Endocrinology and Metabolism 1998 83 2317-2323.

30 Unluhizarci K, Kelestimur F, Bayram F, Sahin Y \& Tutus A. The effects of metformin on insulin resistance and ovarian steroidogenesis in women with polycystic ovary syndrome (see comments). Clinical Endocrinology 199951 231-236.

31 Snorgaard O, Kober L \& Carlsen J. The effect of metformin on blood pressure and metabolism in nondiabetic hypertensive patients (see comments). Journal of Internal Medicine 1997242 407-412.

32 Fritsche A, Schmulling RM, Haring HU \& Stumvoll M. Intensive insulin therapy combined with metformin in obese type 2 diabetic patients (citation of paper in press). Acta Diabetologia 200037 13-18.

33 Inzucchi SE, Maggs DG, Spollett GR, Page SL, Rife FS, Walton V et al. Efficacy and metabolic effects of metformin and troglitazone in type II diabetes mellitus (see comments). New England Journal of Medicine 1998338 867-872.

34 DeFronzo RA, Barzilai N \& Simonson DC. Mechanism of metformin action in obese and lean noninsulin-dependent diabetic subjects. Journal of Clinical Endocrinology and Metabolism 199173 1294-1301.

35 Kahn SE, Prigeon RL, McCulloch DK, Boyko EJ, Bergman RN, Schwartz MW et al. Quantification of the relationship between insulin sensitivity and beta-cell function in human subjects. Evidence for a hyperbolic function. Diabetes 199342 1663-1672.

Received 2 October 2000

Accepted 16 February 2001 